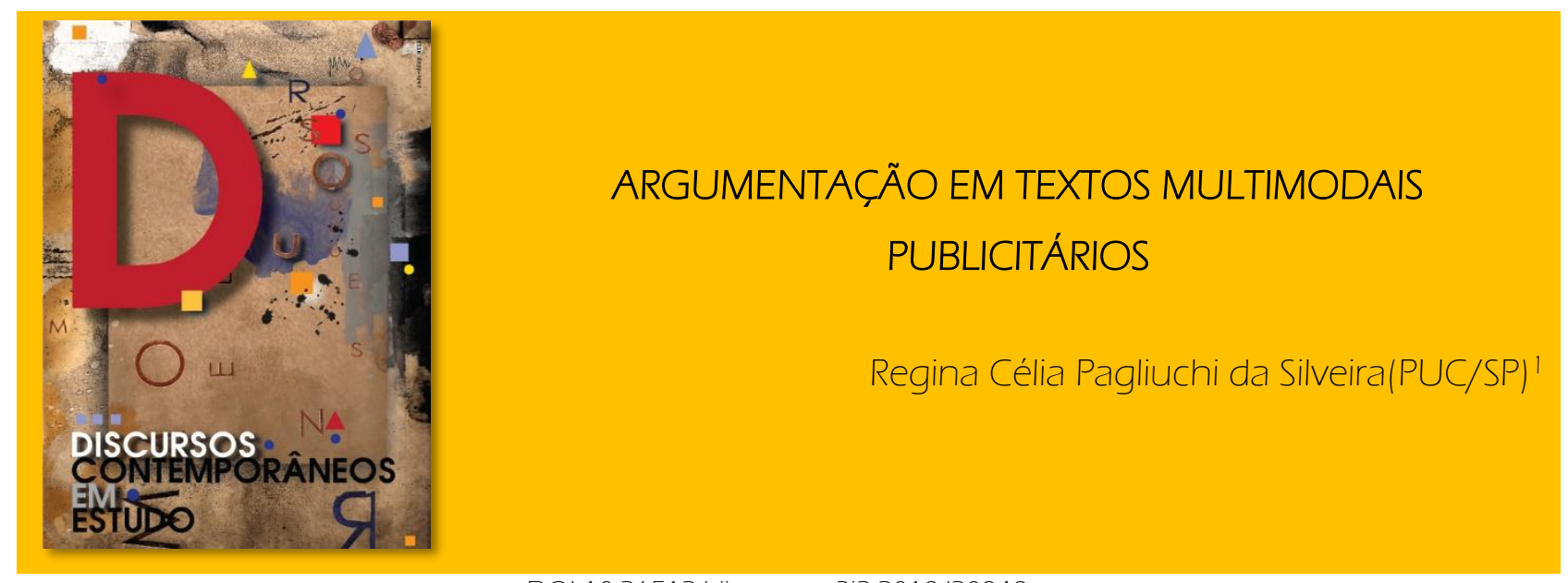

DOI 10.26512/discursos.v3i2.2018/20949

Data de submissão: 17 de junho de 2018 Data de aceite: 10 de novembro de 2018

Resumo: Este texto está situado nas vertentes sócio cognitiva e Semiótica Social da Análise Crítica do Discurso e tem por tema a composição argumentativa de anúncios publicitários multimodais impressos. Objetiva-se examinar a inter-relação imagem, cores e palavras; analisar a distribuição dos elementos textuais em sua espacialização e verificar as estratégias argumentativas utilizadas na produção textual. Justifica-se a pesquisa, devido à preferência dada aos textos multimodais na pós-modernidade, de forma a merecerem estudos para se entender, com um enfoque interacional, a sua produção/compreensão. Entende-se que todas as formas de conhecimento são produzidas no e pelo discurso, sendo que as cognições sociais são tanto grupais como extragrupais. Com um procedimento teórico-analítico, os resultados foram obtidos por método qualitativo. Tais resultados indicam que o texto publicitário multimodal é construído com um conjunto de estratégias argumentativas guiadas para produzir a sedução do outro, transformando-o em consumidor.

Palavras-chave: Discurso publicitário. Textos multimodais impressos. Estratégias argumentativas. Informatividade. Ideologia.

Abstract: This paper is located in the socio cognitive aspects and Social Semiotics of Analysis Critical Discourse, and has the theme argumentative composition printed multimodal commercials. The objective is to examine the interrelationship image, colors and words; analyze the distribution of textual elements in their spatial distribution and verify the argumentative strategies used in textual production. It is appropriate to search, due to the preference given to multimodal texts in postmodernity in order to deserve studies to understand, with an interactional approach, its production / understanding. It is understood that all forms of knowledge are produced in and through discourse, and social cognitions are both group as extragroup. With a theoretical and analytical procedure, the results were obtained by qualitative method. These results indicate that the multimodal text advertising is built with a set of argumentative strategies guided to produce the seduction of another, transforming it into a consumer.

Keywords: Advertising discourse. Printed multimodal texts. Argumentative strategies. Informativeness. Ideology

\footnotetext{
I Doutora em Letras pela Pontifícia Universidade Católica de São Paulo (1974); professora titular do Departamento de Português da Pontificia Universidade Católica de São Paulo.
} 


\section{Considerações iniciais}

Este texto, com base na proposta da Análise Crítica do Discurso (ACD), com suas vertentes sócio-cognitiva e Semiótica Social, trata da composição textual de anúncios publicitários multimodais impressos, delimitada às estratégias argumentativas utilizadas para situar o lugar da sedução do futuro consumidor da ideia/produto anunciados. Tem-se por pressuposto que a linguagem do texto publicitário, ao mesmo tempo que seduz e influencia, também revela ideologias. Este texto tem por objetivo geral contribuir com os estudos da argumentação no discurso publicitário e por objetivos específicos: 1. Examinar a inter-relação imagem, cores e palavras; 2. Analisar a distribuição dos elementos textuais em sua espacialização; 3. Verificar as estratégias argumentativas utilizadas na produção textual.

presente trabalho foi realizado com método qualitativo num procedimento teóricoanalítico. O material foi selecionado em revistas nacionais de grande circulação e é composto por anúncios publicitários impressos.

A ACD, embora constituída por diferentes vertentes, objetiva analisar discursos públicos cujos textos, com grande circulação entre os grupos sociais, produzem o domínio das mentes das pessoas, devido ao poder. A ACD postula uma dialética entre o social e o individual, diferenciando discursos públicos institucionalizados de eventos discursivos particulares: o social guia o individual e este modifica o social, dinamicamente.

O discurso publicitário tem facilidade de acesso ao público, devido à sua grande circulação. Esse discurso tem por definição um macro-ato de fala, ou seja, transformar os seus interlocutores em consumidores e obter lucro para a empresa que quer vender o seu produto.

Os resultados apresentados são parciais e participam de uma pesquisa mais ampla sobre a argumentação em diferentes gêneros textuais do discurso publicitário. Tais resultados são apresentados a seguir e a título de exemplificação foi selecionado um anúncio da GVT com a Vivo (ver anexo), publicado no número 167 da revista GOL linhas aéreas inteligentes, p. 37. Essa peça publicitária anuncia um serviço a ser consumido. GVT é o nome de uma empresa brasileira, pertencente ao grupo francês Vivendi, que presta serviços de telecomunicação, em quase todo nosso território nacional, voltados para o mercado doméstico e empresarial. Um dos serviços é Smart VIVO que oferece internet de Banda larga de ultra velocidade (até 100mbps), portabilidade numérica e soluções de telefonia e internet para o mercado corporativo. 


\section{O discurso publicitário}

A publicidade é uma mensagem paga, veiculada nos meios de comunicação (mídia), que cristaliza uma marca comercial, para um público-alvo (consumidor) previamente selecionado, utilizando recursos linguísticos de ordenação, persuasão e sedução, através de apelos racionais e emocionais. Toda a estrutura publicitária multimodal sustenta uma argumentação icônicolinguística.

O anúncio publicitário compreende uma forma de diálogo com uma relação assimétrica na qual o locutor, embora use o imperativo, transmite uma mensagem alheia a si próprio. verdadeiro produtor permanece ausente da cena enunciativa assim como seu interlocutor; este é atingido pela intenção do produtor, sem ter direito de tomar seu torno nesse diálogo.

No que se refere às relações interpessoais das condições de produção discursiva, SANT'ANNA (2011) afirma que o anúncio publicitário é o que vende um produto para ser consumido; já a propaganda vende serviços. No Brasil, de forma geral, os serviços são vendidos como produtos; logo, termo publicidade abarca a propaganda. Para o autor, esse anúncio cria para seu auditório uma necessidade que será satisfeita, em pouco tempo e com pouco custo, com o consumo do produto anunciado. Para tanto, impõe, nos explícitos e implícitos, valores, mitos, ideais e outras elaborações simbólicas, utilizando recursos multimodais que the servem de veículo. Segundo SANDMANN (1999, p.34):

Sendo a linguagem da propaganda até certo ponto reflexo e expressão da ideologia dominante, dos valores que se acredita, ela manifesta a maneira de ver o mundo, de uma sociedade, em certo espaço da história. Abordando essa questão sob outro ângulo, poderíamos perguntar que aspirações humanas a linguagem da propaganda procura alimentar, satisfazer ou de que aspirações humanas ela procura vir ao encontro, sempre com o objetivo de vender uma ideia e, mais comumente até do que isso, um produto ou serviço.

O principal recurso utilizado no anúncio publicitário é a argumentação que, por meio da especificidade do seu discurso, produz efeitos de sentido, visando alcançar seu maior objetivo, persuadir e aludir o inpúblico-alvo à aquisição do referido produto ou serviço em questão ou mesmo uma simples mudança de pensamento/comportamento. 
A argumentação é o direcionamento que o locutor faz, com o objetivo de levar seu interlocutor a chegar à conclusão que ele deseja. Segundo CITELLI (2003, p.7-8),

Convencer e persuadir, através do arranjo dos diversos recursos oferecidos pela língua. é, numa formulação muito simples, a marca fundamental do texto argumentativo. Percebe-se, nessa medida, por que a linguagem é uma forma de ação e os textos argumentativos são modalidade onde se exerce com maior vigor a persuasão.

\section{A argumentação e o gênero textual-discurso anúncio publicitário impresso}

Os textos diferenciam-se entre si pelos gêneros textuais- discursivos, decorrentes dos usos que esses textos têm em sociedade, ou seja, como formas discursivas que são ligadas às esferas da vida social. Segundo estudiosos do gênero, as pesquisas devem ser realizadas para responder a seguinte pergunta: Por que os membros discursivos constroem textos da maneira como são feitos?

A pesquisa realizada indica que o anúncio publicitário é um gênero textual-discursivo cuja composição textual segue o esquema mental que formaliza a lexia de designação (cf. Pottier, 1974), pois o produto enunciado recebeu uma designação e o público-alvo precisa memorizá-la com um determinado conteúdo semântico. Dessa forma, o texto traz explicitadas expressões visuais de imagens e cores, combinadas com as verbais, a fim de construir, com cada qual, o conteúdo da designação lexical dada ao produto anunciado no texto publicitário, pois tal designação e seu conteúdo não participam do léxico da língua. Assim, a estratégia argumentativa do anunciante é selecionar, nas cognições sociais, elementos com valores sociais positivos para compor o seu texto, assim como insatisfações sociais com as quais o anunciante constrói, para os interlocutores, a necessidade que precisa ser suprida pela aquisição do produto. Sendo assim, o anunciante recorre a uma série de estratégias argumentativas que objetivam formar e mudar a opinião do público-alvo.

No texto exemplificado:

\section{- designação: GVT com a Vivo \\ - conteúdo :}

Categorema: com a GVT, sua empresa tem internet com altas velocidades, agilidade e qualidade.

Semema:

sema 1: Suporte técnico 24 horas por dia, 7 dias da semana;

sema2: Internet corporativa dedicada com altas velocidades; 
sema3: Relatórios online para acompanhamento de performance;

sema4: Roteador GVT incluso;

sema5: Quanto maior o tempo de contrato menor o valor pago;

sema6: Muita economia para sua empresa crescer ainda mais.

Virtuema: o melhor serviço, para seu sucesso comercial, com pouco custo.

O semema, com seus semas, complementa o enunciado de ancoragem temática do texto, designado posicionamento. Este constrói a representação do produto ou serviço anunciado, para o público-alvo. No texto exemplificado, ocorre: "Conte com a gente para ter a economia que seu negócio precisa". Sendo assim, o serviço oferecido está ancorado em "mercado". A seleção das palavras é muito importante para se criar o lugar da sedução ao consumo. Sendo assim, "mercado" está expandido por: "economia necessária, seu negócio".

O lugar da sedução é expandido pela explicitação de cada sema que compõe o semema textual, de forma a atrair o consumidor, disseminando conhecimentos sociais que favorecem a venda do produto anunciado.

Cada sema é um argumento de legitimidade para atribuir o valor de veracidade ao enunciado textual e criar no outro o <<querers> comprar o que the é oferecido. Os argumentos são de legitimidade, pois são construídos com as cognições sociais, ou seja, o público-alvo sabe que necessita de apoio técnico, durante todo o tempo, de altas velocidades na internet, com pouco custo e com grande rendimento para seus negócios, a fim de se obter lucro na área comercial. Esse "saber" é selecionado das cognições sociais cujo marco é indiscutível. Assim, cria-se a necessidade de consumo, levando o outro a acreditar que ele tem essa necessidade pessoal, que é progredida semanticamente no texto pela promessa da sua satisfação plena, em pouco tempo e com pouco custo.

Dessa forma, o fator emotivo acaba sendo envolvido, pois mais do que desejar, o interlocutor é levado a acreditar que precisa de fato de determinado produto ou serviço.

Para tanto, precisa constituir um texto intimamente ligado ao interlocutor, para transformá-lo em consumidor; portanto, o principal objetivo a ser atingido é persuadir o interlocutor a consumir seu produto ou serviço.

Sendo assim, a estratégia argumentativa é a seleção das predicações e das expressões que iram constituir os semas do semema textual, desse gênero textual-discursivo, o anúncio publicitário multimodal impresso.

Por essa razão, MUCCHIELLI (1978, p.23) afirma: 
A publicidade e a propaganda fazem-se passar por informação ou educação, mas seu objetivo real não é transmitir uma mensagem e sim utilizar a comunicação (com todos os seus recursos) para orientar os indivíduos e seus grupos, a fim de levá-los a agir na direção esperada.

A estratégia da repetição desse anúncio, na mídia, guia os interlocutores a memorizá-lo como uma lexia da língua. Logo, pela argumentação, o anúncio publicitário constrói, para seu público-alvo, um lugar de sedução a partir dos significados que compõem o conteúdo da designação nova, atribuída ao produto anunciado, formalizando-o em uma lexia lexical "nova" que passa a circular na sociedade como uma unidade linguística lexical, disseminando valores e conhecimentos sociais que favorecem a compra do produto anunciado.

\section{Princípios da argumentação publicitária}

Os resultados obtidos das análises indicam que a estrutura persuasiva do anúncio publicitário multimodal impresso está baseada nos princípios aristotélicos: o apelo à emoção, o oferecimento da prova e o apelo à credibilidade do comunicador.

O appelo à emoção, na verdade, é um apelo por valores, isto é, aquilo que os consumidores valorizam e que estão procurando nos produtos. Eles decorrem de fatos socioculturais, cuja produção de sentidos se faz através do senso comum, compartilhado, ou seja, cognoscível entre anunciante e público-alvo.

No texto exemplificado, da cognição social é selecionado o valor positivo atribuído ao "sucesso comercial", pois no atual contexto sócio histórico brasileiro ocorre o predomínio de crise econômica e política. A seleção é feita para expressar "conte com a gente para ter a economia que seu negócio precisa", pois GVT da Vivo tem baixo custo e grande rendimento.

A seleção de "a gente" por "nós", apela para a intimidade dos interlocutores com o anunciante, propiciando seduzir o público-alvo ao apelo por valores, aquilo que os consumidores valorizam e que estão procurando nos produtos.

oferecimento de provas é a afirmação das razões ou evidências de por que o produto trará os benefícios que promete; é uma afirmação das características do produto.

No texto exemplificado, o oferecimento de provas é realizado pela inter-relação das imagens com o verbal. O texto está composto por seis segmentos: 
- Segmento 1, à esquerda em cima, o verbal: "conte com a gente para ter uma economia que seu negócio precisa";

- Segmento 2, à direita em cima, imagens e cores: na parte superior um homem bonito, bem cuidado, com barbas e com roupas elegantes e distintas, relógio de marca, olha atentamente para a tela deum tablete que segura com a mão esquerda e opera com a direita. Seu semblante é de tranquilidade, representando o êxito na sua comunicação online;

- Segmento 3, à direita no meio, as predicações atribuídas à GVT, agora com a Vivo;

- Segmento 4, à esquerda no meio, uma moça loira muito bonita e bem vestida, com distinção, falando no telefone celular, com uma fisionomia feliz, tranquila e muito sorridente, olhando para o lado.

- Segmento 5, em baixo à direita, verbal: “GVT agora com a Vivo;

- Segmento 6, na parte inferior, a imagem do mesmo homem do segmento 2, mas centrado, muito atento, sentado na frente de um computador que está sendo operado por ele.

A inter-relação das imagens com o verbal constroem o oferecimento de provas para que o apelo à emoção seja aceito. As imagens usando internet estão obtendo sucesso na sua comunicação online, dando a elas "a felicidade". Essas imagens complementam os segmentos verbais das predicações e da ancoragem do texto.

a apelo à credibilidade do comunicador é um apelo à honestidade e à integridade do anunciante. Trata-se de oferecer as razões para alguém acreditar no que o anunciante disse nos dois primeiros passos do processo de persuasão, por argumentos já dados. Isso inclui referências à Iongevidade do anunciante, o uso de testemunhas e endossos de especialistas.

No texto exemplificado, na parte inferior do anúncio tem-se, à direita: ligue 080000006000 , gvt.com.br/internet; (na parte inferior) telefonia fixa; internet; dados; data center; conexão móvel; respeito.

\section{Argumentação, informatividade e ideologia}

Segundo Kress e van Leeuwen (2001), o texto multimodal oferece várias orientações de leitura, dependendo da distribuição e do tamanho das imagens, sua nitidez, suas cores e figura e fundo. Tratar das cognições sociais implica tratar de valores e de ideologia que estão presentes no discurso publicitário. 
No que se refere à construção espacial do texto multimodal, os autores propõem, entre outros, analisar:

- na linha horizontal: à direita, o "novo" e à esquerda o "dado";

- na linha vertical: em cima, o "ideal que se deseja” e em baixo, o "concreto existente".

- fora das imagens, a moldura; dentro, as imagens que apresentam saliência pelas cores e tamanhos;

- pela focalização das imagens e das cores, as relações de proximidade e afastamento com o interlocutor: de cima para baixo; à altura dos olhos, de baixo para cima.

No texto exemplificado, a organização espacial faz parte das estratégias argumentativas:

À direita, o "novo", o verbal expressa as predicações do conteúdo sêmico novo da designação nova da lexia textual, hierarquizado pela rapidez de comunicação e pouco custo, pois a Vivo está, agora, com a GVT. Essa estratégia é importante, pois se trata de um anúncio impresso de revista que ao ser manuseada, folheia-se lendo a parte direita das páginas.

Em cima, o "ideal" desejado que participa das cognições sociais do brasileiro atual, vivendo uma crise econômica: “Conte com a gente para ter a economia que seu negócio precisa”. ○ “dado": A Vivo presta o melhor serviço para seu negócio ter sucesso com rapidez.

Em baixo, o “concreto”, o que já é de conhecimento público: "telefonia fixa, internet, dados, data center, conexão móvel, respeito", complementado por: "ligue 08000006000 , gvt.com.br/internet".

anúncio exemplificado é construído por partes que se encaixam entre si, oferecendo, argumentativamente, uma orientação de leitura para o texto: o GVT é usado tanto por homens quanto por mulheres jovens, de forma a representar um preconceito em relação ao "velho", pois os jovens é que recorrem às altas tecnologias para obter sucesso. O homem que processa um tablet é apresentado de baixo para cima; a moça está acima dos olhos do expectador; o rapaz em baixo, está na altura dos olhos do expectador. Essa focalização das imagens é argumentativa, pois a que està à altura dos olhos do expectador representa a seriedade e a atenção de um homem que realiza um negócio, sentado na mesa do seu escritório, utilizando um computador; a que está acima, representa a satisfação do mesmo homem acima, de pé, vestido com camisa de manga comprida e enrolada até os cotovelos, comunicando-se por um tablet que segura com as mãos. Em ambas as imagens, o homem está atento olhando, respectivamente a tela do computador e do tablet. Á esquerda, entre as imagens masculinas está uma moça muito bem vestida e penteada, utilizando o celular. Seu sorriso é de alegria que expressa a sua satisfação em estar falando com alguém. Seu olhar não está direcionado para o interlocutor-leitor; diferentemente das imagens masculinas, a 
feminina não demonstra seriedade, atenção ao que está fazendo. Sendo assim, não Ihe é atribuído o valor social de um homem de negócios, revelando um preconceito machista.

Para finalizar, pode-se dizer que o gênero textual anúncio publicitário multimodal, por ser orientado pelo macroato de fala "transformar o interlocutor em consumidor, pela sedução" é produzido com diferentes estratégias argumentativas que atuam desde a seleção dos elementos a serem expressos no texto, até atingir a sua distribuição espacial e temporal. É necessário dar continuidade à pesquisa para se poder verificar as modalidades que envolvem essas estratégias argumentativas em diferentes condições de produção discursiva.

\section{Referências}

CITELLI, A. O texto argumentativo. São Paulo, SP: Editora Scipione, 2003.

KRESS, G.; VAN LEEUWEN, T. Multimodal discourse: the modes and media of contemporary communication. London: Arnold, 2001.

POTTIER, B. Presentation de la lingüística. Madrid: Alcalá, 1974

SANT'ANNA, A.; ROCHA JÚNIOR,I.; GARCIA,L. F. D. Propaganda: teoria, técnica e prática. 8a ed. revista e ampliada. São Paulo: Pioneira, 2011.

MUCCHIELLI, R. A psicologia da publicidade e da propaganda. Rio de Janeiro: Livros Técnicos e Científicos, 1978.

SANDMANN, A. J. A linguagem da propaganda. 3a ed., São Paulo: Contexto, 1999. 
Anexo

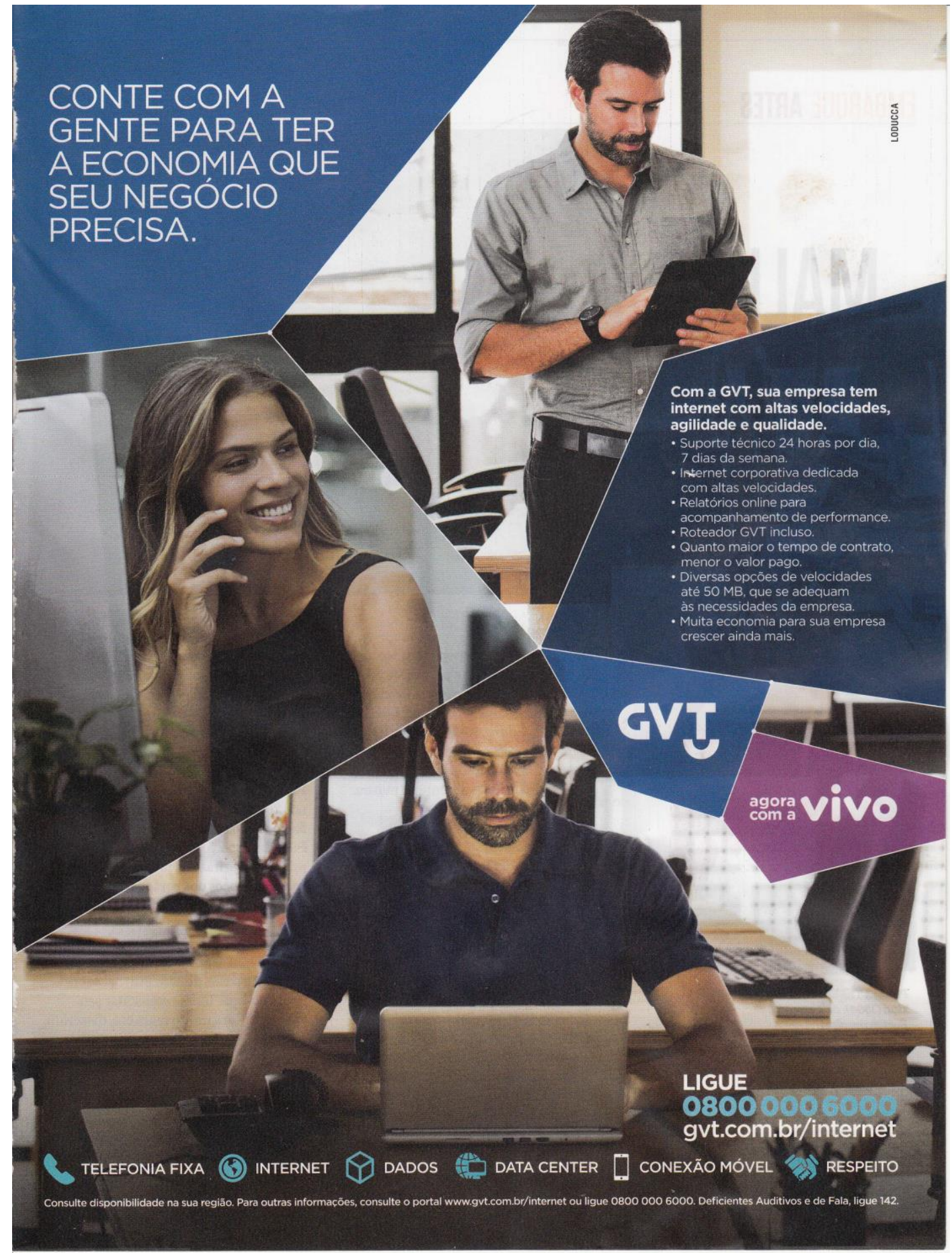

